\title{
Th1 Cytokine Production Induced by Lactobacillus acidophilus in BALB/c Mice Bearing Transplanted Breast Tumor
}

\author{
Abbas Ali Imani Fooladi ${ }^{1}$; Mohammad Hossein Yazdi ${ }^{2}$; Mohammad Reza Pourmand ${ }^{3}$; \\ Abbas Mirshafiey ${ }^{3}$; Zuhair Mohammad Hassan ${ }^{4}$; Taghi Azizi ${ }^{5}$; Mehdi Mahdavi ${ }^{6}$; \\ Mohammad Mehdi Soltan Dallal ${ }^{3,7, *}$ \\ ${ }^{1}$ Applied Microbiology Research Center, Baqiyatallah University of Medical Sciences, Tehran, IR Iran \\ ${ }_{3}^{2}$ Department of Research and Development, Pasteur Institute of Iran, Karaj, IR Iran \\ ${ }^{3}$ Department of Pathobiology, School of Public Health, Tehran University of Medical Sciences, Tehran, IR Iran \\ ${ }^{4}$ Department of Immunology, School of Medical Sciences, Tarbiat Modares University, Tehran, IR Iran \\ 5 Department of Pathology, School of Medical Sciences, Baqiyatallah University of Medical Sciences, Tehran, IR Iran \\ 6 Deaprtment of Immunology, Pasteur Institute of Iran, Tehran, IR Iran \\ 7 Food Microbiology Research Center, Tehran University of Medical Sciences, Tehran, IR Iran \\ ${ }^{*}$ Corresponding author: Mohammad Mehdi Soltan Dallal, Food Microbiology Research Center, Tehran University of Medical Sciences, Tehran, IR Iran. Tel/Fax: +98-2188068924, \\ E-mail: msoltandallal@gmail.com
}

Received: January 4, 2014; Revised: December 29, 2014; Accepted: January 20, 2015

\begin{abstract}
Background:The immunomodulative effects of Lactic Acid Bacteria as probiotics have been already demonstrated.
Objectives: The current study aimed to evaluate the effect of oral administration of Lactobacillus acidophilus on the immune responses and patterns of cytokine production in the BALB/c mice bearing breast cancer.

Materials and Methods: The current study used thirty inbred BALB/c mice, six- to eight-week-old; they were divided into two groups of 15 each. One group was used as control in each assay. The L. acidophilus (ATCC4356) used in the study was inoculated in MRS broth and cultivated overnight at $37^{\circ} \mathrm{C}$ under anaerobic conditions, then collected by centrifugation, and re-suspended in Phosphate-buffered Saline (PBS) media. After preparation of the proper amount of the suspension, it was orally administered to the mice via gavage and the control mice received an equal volume of PBS in the same manner.

Results:The results showed that oral administration of L.acidophilus as a potent immunostimulator agent could motivate the proliferation of immune cells. Moreover, it could increase the production of IFN- $\gamma$ and decrease the production of IL-4, known as Th2 cytokines, in the spleen cell culture. The results showed that the survival time of the L. acidophilus administered mice significantly increased in comparison to that of the control mice.

Conclusions: The current study findings suggested that L. acidophilus can promote immune responses with Th1 bias and may increase the antitumor response. Further, the consumption of this probiotic strain may help to manage the immune response in tumor condition, but more studies are needed to investigate the other mechanisms of this effect.
\end{abstract}

Keywords: Lactobacillus acidophilus; Breast Cancer; IFN- $\gamma$; Immunomodulation

\section{Background}

Breast cancer is one of the most common malignancies and the second cause of death in female patients worldwide. In spite of the advances in understanding many of the involved factors in breast cancer development, this type of cancer still remains as a life threatening disease in females, particularly in the western countries. According to the results of some studies, environmental factors such as diet contribute to the prevalence of breast cancer (1). Consumption of probiotics in dairy products may help the body to inhibit the growth of many types of solid tumors because of their immunomodulative property (2).

Lactic acid bacteria (LAB) are the most commonly used microorganisms as probiotics. They are non-pathogenic bacteria and when administered in adequate amounts, exert health benefits in their host. LAB strains can modulate the immune responses and modify the immune mechanisms (3). Different strains of LAB can also enhance both innate and adaptive immunities. Some of the modifications can promote the antitumor responses. For instance, regulation of innate immunity may be an effective means to prevent cancer. Some studies indicate that immunomodulatory properties of LAB and the pattern of immunomodulation depend on the bacterial species (4). Moreover, many studies have demonstrated the effects of dose and viable or killed probiotic administration on the immune responses (5). The results of some studies show that orally administered lactobacilli affect T-helper 1 and

Copyright (C) 2015, Ahvaz Jundishapur University of Medical Sciences. This is an open-access article distributed under the terms of the Creative Commons Attribution-NonCommercial 4.0 International License (http://creativecommons.org/licenses/by-nc/4.0/) which permits copy and redistribute the material just in noncommercial usages, provided the original work is properly cited. 
T-helper 2 pathways by local cytokine production like IFN- $\gamma$ or TGF- $\beta$ in the gut (6). In addition, it is known that oral administration of certain strains of LAB can increase not only the local immune responses in the intestine, but also the systemic immune responses (7).

\section{Objectives}

However, there are only a few reports about the probiotics and their capacity for breast cancer prevention. The current study aimed to evaluate the direct effect of oral administration of viable Lactobacillus acidophilus on the immune responses, particularly on cytokine production in the splenocytes of BALB/C mice bearing breast cancer tumor.

\section{Materials and Methods}

\subsection{Animals}

The current study used thirty female inbred BALB/C mice, six- to eight-week-old and weighing 25 - 30 grams, obtained from the Pasture Institute of Iran (Tehran, Iran); they were divided into two groups of 15 each as the case and the control. The mice were kept in plastic cages, allowed for free access to water, and maintained on a 12:12 light-dark conditions in the whole period of the study. The temperature and humidity were controlled at $23 \pm$ $1^{\circ} \mathrm{C}$ and $55 \pm 10 \%$, respectively. All mice were fed with standard mice pellet diet and this experiment was approved by the Institutional Animal Care and Use Committee in Tehran University of Medical Science (Tehran, Iran).

\subsection{Microorganism and Feeding Procedure}

The L. acidophilus ATCC4356 strain used in the study was purchased from the Persian type culture collection (Iranian Research Organization for Science and Technology, Tehran, Iran). The strain was inoculated in $10 \mathrm{~mL}$ of DeMan-Rogosa-Sharpe (MRS) broth (Merck, Germany) and cultivated overnight at $37^{\circ} \mathrm{C}$ under anaerobic conditions, then centrifuged and washed three times with phosphate buffer saline (PBS) and re-suspend in PBS. After preparation of a proper amount of the suspension, it was orally administered to the mice with a gastric feeding tube. The control mice received an equal volume of PBS during the study. The probiotic group was given 0.5 $\mathrm{mL}$ of the suspension containing $2.7 \times 108 \mathrm{CFU} / \mathrm{mL}$ L. acidophilus every day starting from two weeks before tumor transplantation, which was continued with three day intervals and seven consecutive days feeding until the day 30. The control group was given an equal volume of PBS with the same procedure similar to the controls.

\subsection{Tumor Transplantation}

The mice bearing breast tumor (8) were used as the tumor stock. After cervical dislocation, the tumors were removed aseptically, dissected into $0.5 \mathrm{~cm}^{3}$ pieces with scalpel and washed three times with sterile PBS. The experimental mice were anesthetized with ip injection of ketamine and xylene (10 $\mathrm{mg} / \mathrm{kg}$ of body weight) and the tumor pieces were transplanted subcutaneously to the right flank of the mice.

\subsection{Cytokine Determination in Spleen Cell Culture}

The spleens were removed aseptically exactly after the 30th day of tumor transplantation. The experimental mice were sacrificed and their spleens were homogenized in Hanks' balanced salt solution (Sigma, Germany). The splenocytes were sedimented by centrifugation, resuspended in red blood cell lysing buffer (Sigma, Germany) for 5 minutes, washed and re-suspended in RPMI 1640 medium (Gibco Life Technologies, Germany), supplemented with $10 \%$ FBS and $100 \mu \mathrm{g} / \mathrm{mL}$ penicillin and streptomycin (Invitrogen, Paisley, Germany). Then spleen cells were estimated at $2.5 \times 106 \mathrm{cell} / \mathrm{mL}$ and incubated alone or treated with $20 \mu \mathrm{g} / \mathrm{mL}$ of tumor antigen for 72 hours in RPMI1640 (Gibco Life Technologies, Germany), then supplemented with 10\% fetal bovine serum (Invitrogen, Paisley, Germany) and 1\% penicillin/streptomycin (Sigma, Germany) at $37^{\circ} \mathrm{C}$ in a humidified atmosphere of $5 \% \mathrm{CO}_{2}$. IFN- $\gamma$, IL- 4 and IL-10 levels of the spleen cell cultured supernatants were detected using ELISA technique (R\&D system, USA) according to the manufacturer's recommendation. In order to provide the tumor antigen, one of the tumor stock mice was used and then the tumor was extracted from its body and dissected into small sections $\left(3 \mathrm{~mm}^{3}\right)$. After that the tumor sections were washed by sterile PBS and fragmented via sonication. Then the protein dialysis method was used in order to extract the proteins from the suspension and the protein concentration was measured by Bradford method (9).

\subsection{MTT Spleen Cell Culture Assay}

The splenocytes culture was prepared as mentioned in pervious section. The cell suspensions containing $1.5 \times 106$ viable cells $/ \mathrm{mL}$ were distributed $(100 \mu \mathrm{L} /$ well $)$ into 96-well tissue culture plates with flat-bottom wells (Costar, Cambridge, Mass.). Phytohemagglutinin (PHA), polyclonal activator, was used at $100 \mu \mathrm{g} / \mathrm{mL}$ as a mitogen (10). After incubation at the humidified $5 \% \mathrm{CO}_{2}$ at $37^{\circ} \mathrm{C}$ for three days, $25 \mu \mathrm{L}$ of 3-(4,5-dimethylthiazol-2-yl)-2,5-diphenyltetrazolium bromide (MTT) was added to each well and the plates were incubated for four hours at the humidified $5 \% \mathrm{CO}_{2}$ at $37^{\circ} \mathrm{C}$; the yellow tetrazolium salt, MTT, was converted into a purple formazan substrate by the mitochondrial enzyme, succinate dehydrogenase (SDH) in the wells containing viable cells. To dissolve the dark formazan crystals, $100 \mu \mathrm{L}$ of Dimethyl sulfoxide (DMSO) was added to each well and the plates were incubated for 10 minutes at $37^{\circ} \mathrm{C}$ under humid conditions. After incubation, the contents of the plates were thoroughly mixed 
for 5 minutes on a plate shaker. The optical density (OD) of each well was read at $570 \mathrm{~nm}$ with a $630 \mathrm{~nm}$ reference, and the stimulation index (SI) was calculated according to the following formula:

Stimulation Index (SI) = the absorbance value of the mitogen - cultures divided by the absorbance value of the non-stimulated cultures

\subsection{Survival Rate}

At the end of the study, seven mice from each group were kept under the standard conditions (fed with standard diet, free access to water and maintained on a 12:12 light-dark conditions) until they died. The daily death of the mice was recorded and after the last death in both groups, the data was analyzed by Kaplan-Meier test.

\subsection{Statistical Analysis}

All statistical analyses, except for the survival rate, were conducted by SPSS 15.0 using a one way ANOVA test. The values are presented as mean \pm SD

\subsection{Ethics Approval}

All experimental procedures involving animals were accepted by the Ethics Committee of Tehran University of Medical Sciences.

\section{Results}

\subsection{Cytokine Assay in Spleen Cell Culture}

The levels of IFN- $\gamma$, IL-4 and IL-10 in the spleen cell culture supernatants were measured using a sandwich ELISA assay. The level of IFN- $\gamma$ in the spleen cell culture supernatants was significantly $(\mathrm{P}=0.005)$ higher in the L. acidophilus group compared with that of the control; while the IL-4 level was lower than that of the control, however the difference was not significant (Figure 1). The IFN- $\gamma /$ IL-4 ratios are also shown in Figure 2, although the level of IL-10 (Figure 3) had no change anymore.

\subsection{Effect of Lactobacillus acidophilus Administra- tion on Splenocyte Proliferation}

The results of PHA-stimulated splenocyte proliferation in both groups of mice are shown in Figure 4. The PHAstimulated splenocyte proliferation in the L. acidophilus administrated mice was considerably higher than that of the PBS control mice. The dose of PHA used as a mitogen in this test was $5 \mu \mathrm{g} / \mathrm{mL}$.

\subsection{Survival Rate}

The results of survival analysis showed a decrease $(\mathrm{P}=$ 0001) in the rate of death or in other words increase in the survival rate among the L. acidophilus group in comparison to that of the controls (Figure 5).
Figure 1. Induction of IFn $\gamma$ and IL4 by Lactobacillus acidophilus Administration in the Spleen Cell Culture
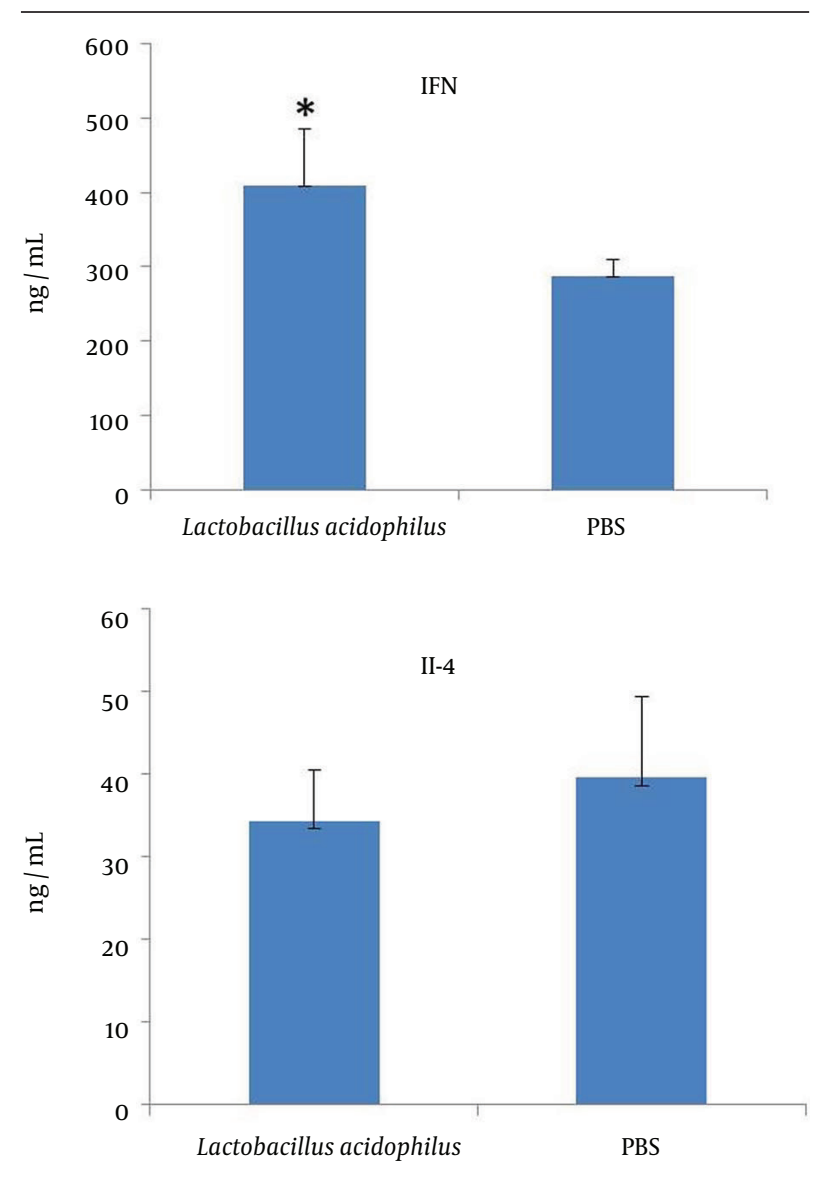

The Spleen cells were cultured for 72 hours at $37^{\circ} \mathrm{C}$ under humidified atmosphere of $5 \% \mathrm{CO}_{2}$ with tumor antigen stimulation and the level of IFN- $\gamma$ and IL4 in the supernatants was determined using ELISA. The data are the means $\pm S D$ of triplicate cultures.

Figure 2. The Increase in IFn $\gamma$ / IL4 Ratio in the Lactobacillus acidophilus Administered Group Display the Stimulation of Th1 Cytokine Production Instead of Th2 Cytokines

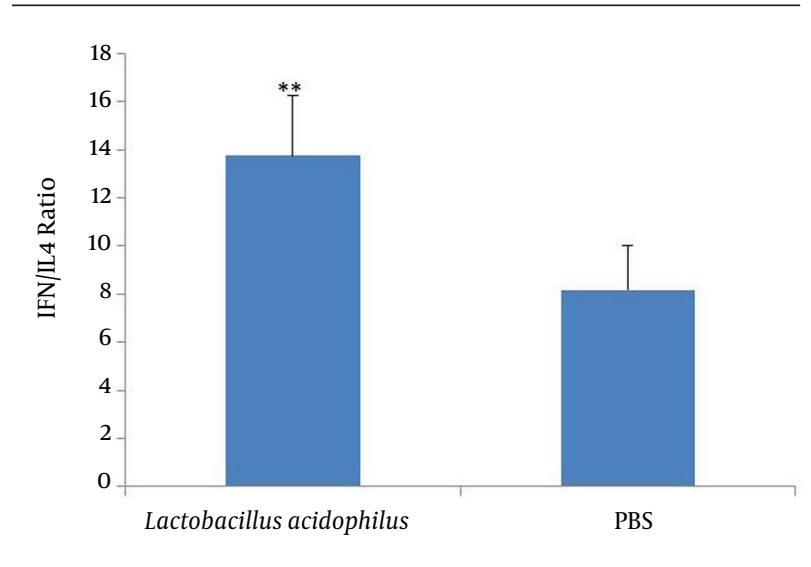

Data represent the means \pm SD for triplicate culture from eight animals per group $(\mathrm{P}=0.028)$. 
Figure 3. Comparison the Level of IL10 Production Between Groups

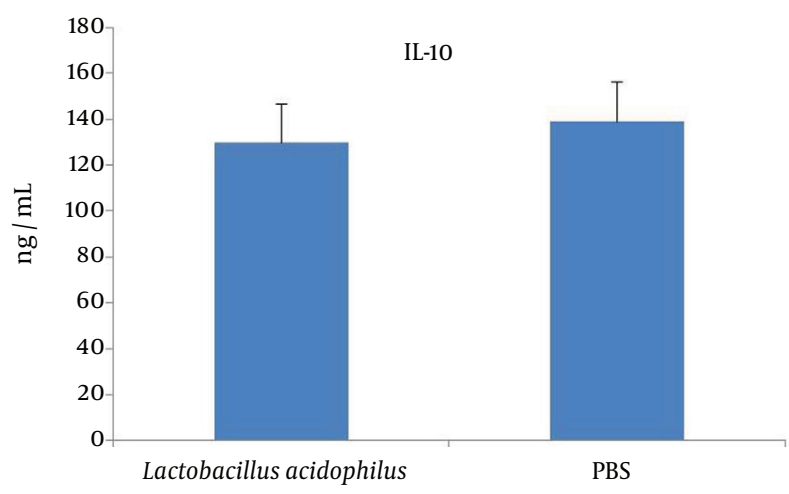

The Level of IL10 Production in the Splenocyte Culture had no Change in the Lactobacillus acidophilus Treated mice in Comparison to that of the Controls. Data represent the means \pm SD for triplicate culture from eight animals per group.

Figure 4. The Effect of Lactobacillus acidophilus Administration on PHAstimulated Splenocyte Proliferation in the Tumor Bearing Mice

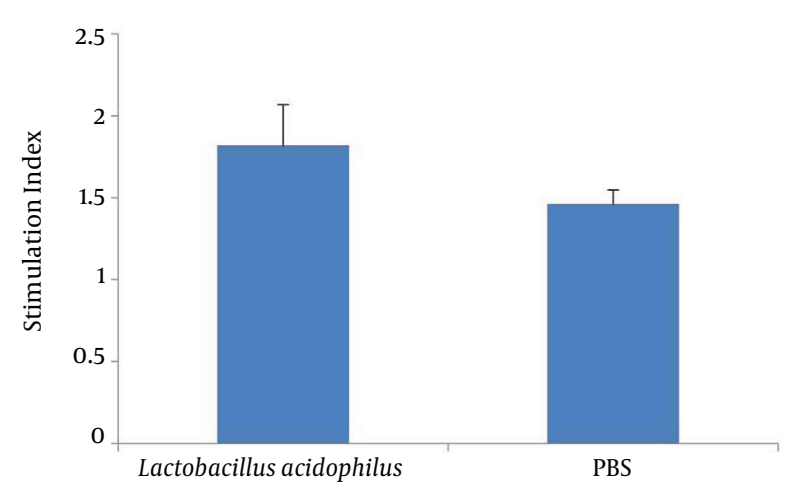

The splenocytes were cultured with PHA as a mitogen (final concentration, $5 \mu \mathrm{g} / \mathrm{mL}$ ). The splenocytes proliferation was measured by MTT method as described in the text. Data represent the means \pm SD for triplicate culture from eight animals per group.

Figure 5. Results of Survival Analysis

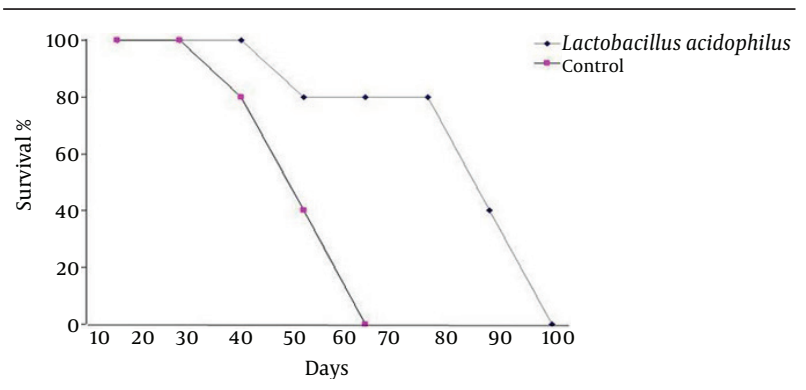

At the end of the study, four mice from each group were kept under standard conditions until they died. The rate of death was registered every day and the obtained data was analyzed with Kaplan-Miere Test after the last death the in both groups. $\mathrm{P}=0.001$ was considered as the level of significance.

\section{Discussion}

Probiotics are friendly microorganisms that when administered in adequate amounts, confer health benefits in their host, according to the World Health Organization and Food and Agriculture Organization definitions (11). Lactic Acid Bacteria (LAB) are the most commonly used microorganisms as probiotics. According to the results of the current study, oral administration of L. acidophilus can promote the immune responses with Th1 dominance via stimulation of the production of pro-inflammatory cytokines such as IFN- $\gamma$, and inhibit the production of anti-inflammatory cytokines like IL-4 and IL-10, which can differentiate the immune responses with Th2 bias. IFN- $\gamma$ is one of the most important Th1 cytokines with a key role in the activation of natural killer cells (NK cells), which are the first immune defense against the tumor cells and viral infections. IFN- $\gamma$ also has an important role in Major Histocompatibility Complex (MHC) expression on the surface of cells.

Since MHC expression diminishes in some tumor cells, specific Cytotoxic T Lymphocyte (CTL) mechanisms cannot detect these cells; therefore, increasing of this cytokine may help the CD8+ T cells to campaign with this type of tumors in addition to activation of NK cytotoxicity. Moreover, high levels of IFN- $\gamma$ can inhibit the intratumoral angiogenesis, which has a critical role in cancer prognosis (12). Besides the increase in the level of IFN- $\gamma$, decrease in IL-4 production in the splenocytes of L. acidophilus administered mice, as an important Th2 cytokine, also indicated the Th1 property of immune response. IL-10 is an anti-inflammatory Th2 cytokine with a key role to inhibit the synthesis of pro-inflammatory cytokines such as IFN- $\gamma$, IL-2, IL-3, TNF $\alpha$ and GM-CSF made by the cells such as macrophages and the type $1 \mathrm{~T}$ helper cells (13). IL-4 decreases macrophage inflammatory activity. It is also an important cytokine in immune regulation. Therefore, decrease of this cytokine in tumor condition may help with better prognosis. LAB are commensal bacteria in the intestine, which have close contact with Gastrointestinal Associated Lymphoid Tissue (GALT).

Many studies indicated the effect of these bacteria on the maturation of immune cells in GALT, and the efficacy of immune responses $(14,15)$. According to some other studies the effect of LAB on the development of immune responses and immunomodulation depends on two facts, first the contact of immune cells particularly the antigen presenting cells (APCs) such as macrophage and dendritic cells (DCs) with the bacterial components that are mostly peptidoglycan (PG) and lipoteichoic acid (LTA) in these bacteria; and secondly on the probiotic's metabolites specially in the fermented foods (16-18). Some investigations indicated that LAB show their effect on the immune status via toll like receptors (TLRs), particularly TLR2 that recognize LTA and PG and TLR9 that recognizes CpG like oligonucleotides, which exist in lactic acid bacteria (19-21).

These bacterial components are recognized by corresponding Toll-like Receptors (TLR), followed by cytokine 
secretion (20). In addition, L. acidophilus administration can affect the proliferation of immune cells in the spleen of mice via stimulation with specific tumor antigens implying that this type of LAB has immunostimulatory properties. This property can be attributed to the presence of LTA antigen as a major component in the cell walls of LAB. Some studies showed tumor-induced immunosuppression (22), and under such conditions, administration of any immunostimulator agent may contribute to the development of efficient immune defense. To confirm the other results of the current study, increase in the survival rate of the L. acidophilus and other Lactobacillus spp. administered mice supported the immunostimulatory and immunomodulatory effects of this strain (23, 24). In conclusion, the results of the study suggested that daily consumption of L. acidophilus may modulate the immune response through its antitumor property and enhance the Th1 cytokine production like IFN- $\gamma$, which is more necessary in tumor condition. But more investigations are needed to understand the other mechanisms of such effects.

\section{Authors' Contributions}

Mohammad Mehdi Soltan Dallal: manuscript preparation; Mohammad Hossein Yazdi: animal works; Mohammad Reza Pourmand and Abbas Mirshafiey: manuscript preparation; Zuhair Mohammad Hassan: supervision of animal work; Abbas Mirshafei: in vitro tests consultation; Abbas Ali Imani Fooladi: participation in all experiments; Taghi Azizi: help in animal works; Mehdi Mahdavi: participation in all tests.

\section{Funding/Support}

This work was supported by the Vice-Chancellor for Research of Tehran University of Medical Sciences, Tehran, IR Iran (Project No:6954).

\section{References}

1. Stewart TH, Heppner GH. Immunological enhancement of breast cancer. Parasitology. 1997;115 Suppl:S141-53.

2. de Moreno de LeBlanc A, Matar C, LeBlanc N, Perdigon G. Effects of milk fermented by Lactobacillus helveticus R389 on a murine breast cancer model. Breast Cancer Res. 2005;7(4):R477-86.

3. Schrezenmeir J, de Vrese M. Probiotics, prebiotics, and synbiotics-approaching a definition. Am J Clin Nutr. 2001;73(2 Suppl):361S-4S.

4. Kirjavainen PV, El-Nezami HS, Salminen SJ, Ahokas JT, Wright PF. The effect of orally administered viable probiotic and dairy lactobacilli on mouse lymphocyte proliferation. FEMS Immunol Med Microbiol. 1999;26(2):131-5.

5. Gill HS, Rutherfurd KJ. Viability and dose-response studies on the effects of the immunoenhancing lactic acid bacterium Lactobacillus rhamnosus in mice. BrJ Nutr. 2001;86(2):285-9.

6. Maassen CB, van Holten JC, Balk F, Heijne den Bak-Glashouwer MJ, Leer R, Laman JD, et al. Orally administered Lactobacillus strains differentially affect the direction and efficacy of the immune response. Vet Q.1998;20 Suppl 3:S81-3.
7. Maassen CB, van Holten-Neelen C, Balk F, den Bak-Glashouwer MJ, Leer RJ, Laman JD, et al. Strain-dependent induction of cytokine profiles in the gut by orally administered Lactobacillus strains. Vaccine. 2000;18(23):2613-23.

8. Feyzi R, Hassan ZM, Mostafaie A. Modulation of $\mathrm{CD}(4)(+)$ and $\mathrm{CD}(8)(+)$ tumor infiltrating lymphocytes by a fraction isolated from shark cartilage: shark cartilage modulates anti-tumor immunity. Int Immunopharmacol. 2003;3(7):921-6.

9. Ernst O, Zor T. Linearization of the bradford protein assay. J Vis Exp. 2010(38).

10. Jimenez-Valera M, Sampedro A, Moreno E, Ruiz-Bravo A. Modification of immune response in mice by ciprofloxacin. Antimicrob Agents Chemother.1995;39(1):150-4.

11. Plaza-Diaz J, Gomez-Llorente C, Fontana L, Gil A. Modulation of immunity and inflammatory gene expression in the gut, in inflammatory diseases of the gut and in the liver by probiotics. World J Gastroenterol. 2014;20(42):15632-49.

12. Angiolillo AL, Sgadari C, Taub DD, Liao F, Farber JM, Maheshwari $\mathrm{S}$, et al. Human interferon-inducible protein 10 is a potent inhibitor of angiogenesis in vivo. J Exp Med.1995;182(1):155-62.

13. Moore KW, de Waal Malefyt R, Coffman RL, O'Garra A. Interleukin-10 and the interleukin-10 receptor. Annu Rev Immunol. 2001;19:683-765.

14. Galdeano CM, Perdigon G. The probiotic bacterium Lactobacillus casei induces activation of the gut mucosal immune system through innate immunity. Clin Vaccine Immunol. 2006;13(2):219-26.

15. Haghighi HR, Gong J, Gyles CL, Hayes MA, Sanei B, Parvizi P, et al. Modulation of antibody-mediated immune response by probiotics in chickens. Clin Diagn Lab Immunol. 2005;12(12):1387-92.

16. Heumann D, Barras C, Severin A, Glauser MP, Tomasz A. Grampositive cell walls stimulate synthesis of tumor necrosis factor alpha and interleukin- 6 by human monocytes. Infect Immun. 1994;62(7):2715-21.

17. Kitazawa H, Matsumura K, Itoh T, Yamaguchi T. Interferon induction in murine peritoneal macrophage by stimulation with Lactobacillus acidophilus. Microbiol Immunol. 1992;36(3):311-5.

18. Rachid M, Matar C, Duarte J, Perdigon G. Effect of milk fermented with a Lactobacillus helveticus R389(+) proteolytic strain on the immune system and on the growth of 4T1 breast cancer cells in mice. FEMS Immunol Med Microbiol. 2006;47(2):242-53.

19. Akira S, Takeda K. Toll-like receptor signalling. Nat Rev Immunol. 2004;4(7):499-511.

20. Karlsson H, Hessle C, Rudin A. Innate immune responses of human neonatal cells to bacteria from the normal gastrointestinal flora. Infect Immun. 2002;70(12):6688-96.

21. Takeda K, Akira S. Toll-like receptors in innate immunity. Int Immunol. 2005;17(1):1-14.

22. O'Hara RJ, Greenman J, MacDonald AW, Gaskell KM, Topping KP, Duthie GS, et al. Advanced colorectal cancer is associated with impaired interleukin 12 and enhanced interleukin 10 production. Clin Cancer Res. 1998;4(8):1943-8.

23. Soltan Dallal MM, Yazdi MH, Holakuyee M, Hassan ZM, Abolhassani M, Mahdavi M. Lactobacillus casei ssp.casei induced Th1 cytokine profile and natural killer cells activity in invasive ductal carcinoma bearing mice. Iran J Allergy Asthma Immunol. 2012;11(2):183-9.

24. Yazdi MH, Soltan Dallal MM, Hassan ZM, Holakuyee M, Agha Amiri S, Abolhassani M, et al. Oral administration of Lactobacillus acidophilus induces IL-12 production in spleen cell culture of BALB/C mice bearing transplanted breast tumour. Br J Nutr. 2010;104(2):227-32. 